\title{
Barn med epilepsi får delt sine erfaringer med EpiSnakk
}

\section{Noen barn med epilepsi kan synes at det er flaut og} vanskelig å fortelle om sykdommen sin. Et nyutviklet elæringsprogram hjelper barna med å sette ord på hvordan de har det.

Merete Lillevand Hem

Fagutviklingssykepleier

Seksjon for barn og ungdom, Spesialsykehuset for epilepsi, Oslo universitetssykehus

Ingeborg Stavn

Fagutviklingssykepleier

Seksjon for barn og ungdom, Spesialsykehuset for epilepsi, Oslo universitetssykehus

Barn Undervisning Epilepsi

\section{Hovedbudskap}

EpiSnakk kan være et godt hjelpemiddel når barn med epilepsi skal sette ord på egen sykdom og formidle kunnskap til familie og venner. Sykepleiere kan bruke EpiSnakk i samtale og undervisning med barna. 
Ved Seksjon for barn og ungdom på Spesialsykehuset for epilepsi (SSE) møter vi mange barn som har behov for kunnskap og veiledning om sin epilepsi. Det har lenge vært behov for nytt materiell til bruk i undervisning og samtaler med barna. Det finnes allerede en del materiell om epilepsi for barn, men lite er elektronisk.

Barn bruker digitale verktøy aktivt i sin hverdag, og for å møte deres behov har vi utarbeidet et e-læringsprogram for barn $\mathrm{i}$ alderen fem-tolv år.

Barn med epilepsi har en lovhjemlet rett til individuelt tilpasset informasjon om sin sykdom. Vi som sykepleiere skal, så langt det er mulig, sikre at barnet får informasjon og har forstått innholdet $(1,2)$. For å kunne ivareta dette er det nødvendig med gode verkt $\varnothing \mathrm{y}$.

\section{Mer kunnskap kan gi økt trygghet}

Studier viser at det varierer hvor mye kunnskap barna har om sin epilepsi $(3,4)$, og hvor mye de ønsker å snakke om sykdommen. Noen synes det er vanskelig å snakke om epilepsi med familie og venner, og frykter at de skal bli møtt med mobbing og fordommer.

I flere studier oppgir barna et ønske om normalitet (4-8). Barnas egne og andres oppfatning av epilepsi som noe som er flaut eller smittsomt, er noe av det som kommer frem i studiene (5).

\section{三 «De fleste barna ønsker å være like godt informert som sine foreldre.»}

Vår erfaring som sykepleiere er at de fleste barna gjerne vil snakke om sin epilepsi. De ønsker å være like godt informert som sine foreldre.

Når barna får mer kunnskap om sykdommen sin, kan de oppleve å bli tryggere. Barnas sykdomsforståelse kan ha betydning for hvordan de håndterer hverdagen (9-12).

Barn kan oppleve at helsepersonell og foreldre snakker sammen uten å involvere dem. Det kan gjøre at de ikke får svar på sine egne spørsmål $(12,13)$. Barn kan også lage seg egne forestillinger og tanker rundt sykdom og behandling som følge av at de bare får med seg bruddstykker av helheten. Dette kan være med på å skape utrygghet. 
Forskning viser at barna opplevde det som positivt hvis foreldrene snakket med dem om epilepsi. Det som kunne gjøre det vanskelig, var når foreldrene hadde en tendens til å holde diagnosen hemmelig, eller at de unngikk å bruke ordet epilepsi og prøvde å benekte barnets tilstand $(14,15)$.

\section{Prosessen frem mot ferdig produkt}

E-læringsprogrammet er resultatet av et kvalitetsforbedringsprosjekt. Det er basert på våre kliniske erfaringer og relevant forskningslitteratur samt idémyldringer med barn, fokusgruppeintervjuer med foreldre og fagkunnskap fra sykepleietjenesten.

Gjennom søk i kunnskapsbaserte oppslagsverk, retningslinjer og Medline fikk vi oversikt over forskningen på området. Forskningen, sammen med våre kliniske erfaringer, dannet grunnlaget for utarbeidelsen av tre ulike intervjuguider som ble brukt ved idémyldringene, fokusgruppeintervjuene og fagtimer med sykepleierne.

\section{三 «Idémyldringene ga oss økt kunnskap om barnas erfaringer og behov.»}

Barna og foreldrene som ble invitert til å være med på idémyldring og fokusgruppeintervjuer, var innlagt ved SSE. Vi gjennomførte fire idémyldringer med til sammen åtte barn. Idémyldringene ga oss økt kunnskap om barnas erfaringer og behov.

Gjennom to fokusgruppeintervjuer med åtte foreldre i hver gruppe fikk vi foreldrenes syn på hva de mener barna har behov for av kunnskap og veiledning. Personalet bidro med sine erfaringer med undervisning og ga innspill til temaer og oppbygning.

Underveis i prosjektet fikk vi tilbakemeldinger fra en tverrfaglig referansegruppe som besto av barnesykepleier, spesialpedagog og psykolog. En mor og et barn gjennomgikk e-læringen før ferdigstillelse.

Litteratur og innspillene dannet grunnlaget for valg av temaer, utarbeidelse av tekst og oppbygning av elæringsprogrammet. 


\section{Barnas innspill formet verktøyet}

Vi valgte navnet EpiSnakk. Det er kort og gjenkjennbart og inviterer til å snakke om og lære mer om epilepsi.

Utarbeidelsen av e-læringsprogrammet har vært et faglig spennende prosjekt. Det tette samarbeidet med både barn, foreldre og fagpersoner ga oss mange gode ideer og flere innfallsvinkler. Barna som deltok i idémyldringene, hadde mange ulike tanker og innspill om epilepsi, som vi har fors $\varnothing \mathrm{kt}$ å ta med oss videre i valg av temaer og i måten vi har forklart ord og uttrykk på.

Dette er noen eksempler på innspill fra barna:

- «Epilepsien er inni hjernen min.»

- «Viktig at en er seg selv og ikke bare en med epilepsi.»

- «Etter GTK blir jeg veldig trett og lurer på hva klokka er. Det er irriterende. Vær rolig, ikke få panikk. Si ifra til en voksen.»

Foreldrene som deltok i fokusgruppeintervjuene, var ekstra opptatt av barnas hverdag med epilepsi. De $\varnothing$ nsket at vi tok med noe om det man ikke ser, og ikke bare om anfall. De hadde fokus på åpenhet og på hvordan man kan fortelle venner om epilepsi.

Fagpersonene var tydelige på at e-læringsprogrammet måtte være enkelt, med korte tekster og gode bilder med klare farger.

Vi fikk i denne prosessen bekreftet at forskningen og våre erfaringer samstemmer godt med innspillene vi fikk. Dette dannet grunnlaget for valg av de åtte ulike temaene $\mathrm{i}$ EpiSnakk.

\section{Hovedtemaer og gjennomgangsfigurer}

De fem hovedtemaene er «Hva er epilepsi?», «Undersøkelser», «Hverdagen vår med epilepsi», «Hvordan kan vi fortelle andre om epilepsi?», og «Hva kan hjelpe mot epilepsi?». De tre siste temaene er «Hva betyr?», «Visste du at ...» og «EpiQuiz». De inviterer barna til undring og til å svare på spørsmål.

EpiSnakk har to gjennomgangsfigurer, Mats og Maja, som barna blir kjent med underveis (se bilde 1). Ulike maler, foto, illustrasjoner og animasjoner skaper variasjon i e-læringen og bidrar til å fange barnas oppmerksomhet. 


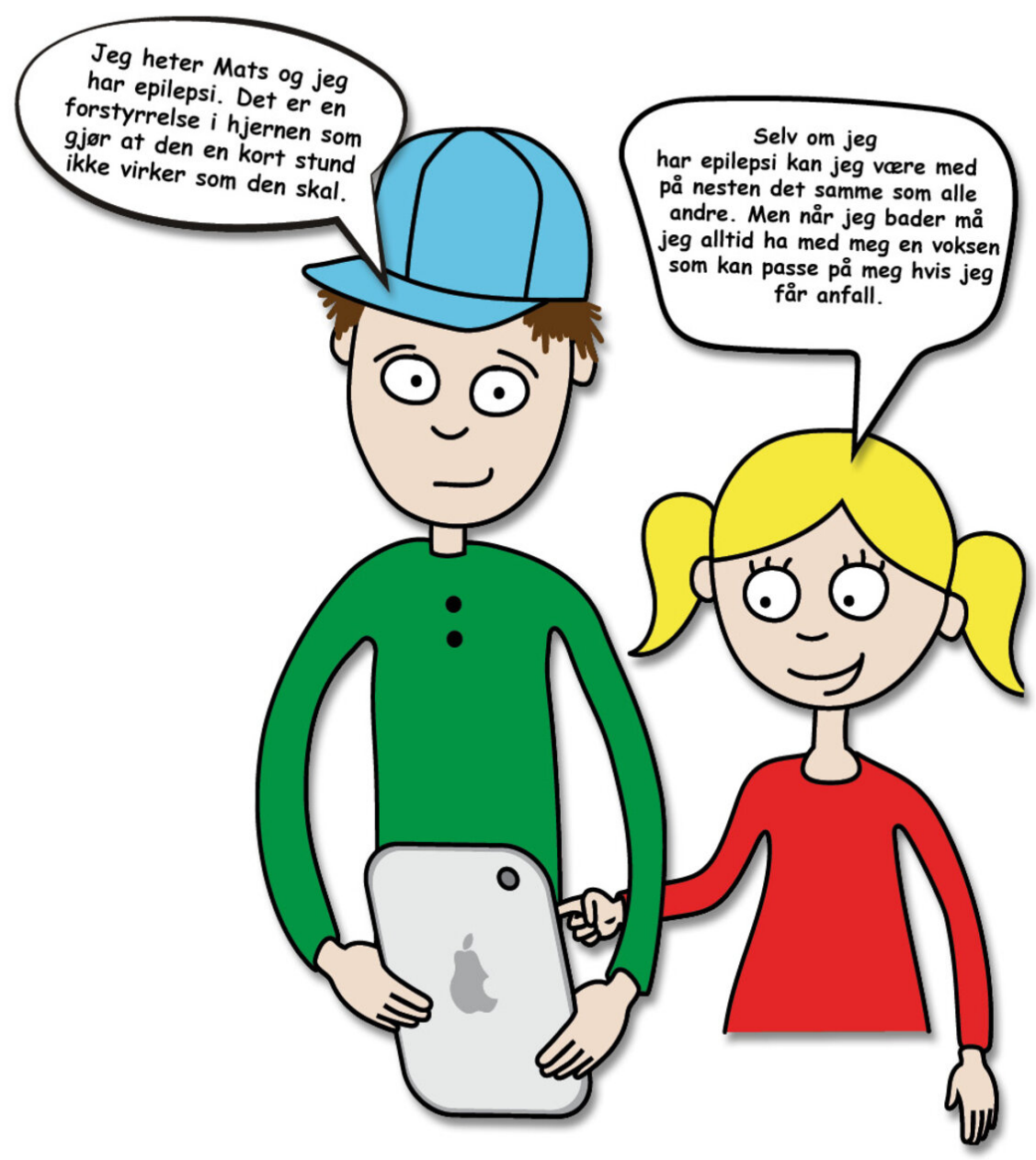

Bilde 1. Mats og Maja er gjennomgangsfigurene i EpiSnakk.

Vi valgte å legge stemmer til all tekst. Dette var et bevisst valg for å kunne nå barn i ulike aldre og med varierende funksjonsnivå. Bruk av barnestemmer gjør at barna lettere kan identifisere seg med figurene. Vi jobbet mye med tekst og valg av ord som barn kan forstå. Innspill fra barn, foreldre og fagpersoner førte til at språket ble mer levende og variert.

\section{Nærmere om de åtte temaene}

E-læringsprogrammet starter med en temaside (bilde 2). Her kan barna velge hvilket av de åtte temaene de ønsker å klikke seg inn på for å lære mer. 


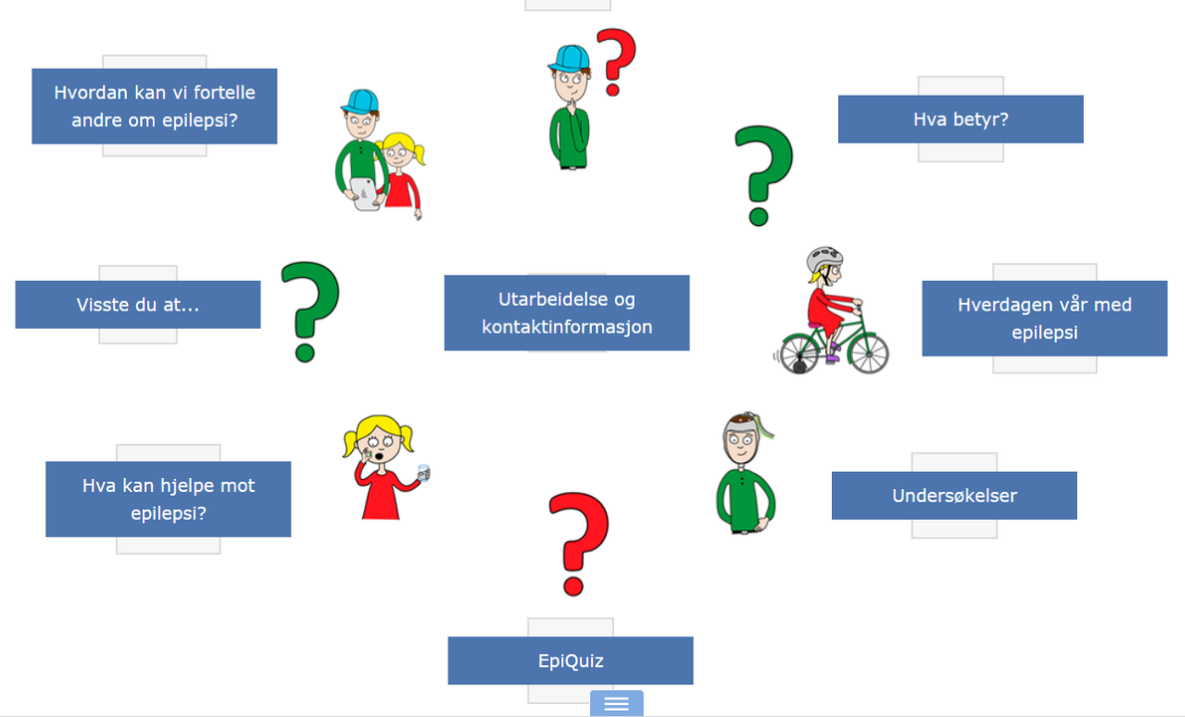

Bilde 2. Fra temasiden kan barna velge hvilket tema de ønsker å lære mer om.

Hva er epilepsi? Under dette temaet får barnet én forklaring, men de får også presentert flere eksempler på barns måter å beskrive epilepsi på.

Vi har erfart at det kan være vanskelig for barna å fortelle andre hva epilepsi er, og vi har derfor valgt å ta med flere ulike forklaringer. De kan også velge å se animasjoner av ulike typer anfall.

Unders $\varnothing$ kelser viser en bildeserie om påkopling av EEG med en kort forklaring til hvert bilde. Den kan brukes ved forberedelse til påkopling eller for å bearbeide opplevelser i etterkant av unders $\varnothing$ kelsen. Barna kan også vise bildene til familie og venner.

Hverdagen vår med epilepsi er sentralt når barna er innlagt ved Seksjon for barn og ungdom ved SSE. Her sier Maja: «Selv om jeg har epilepsi kan jeg være med på nesten det samme som alle andre», mens Mats sier: «Det er ikke så farlig å bli sliten, men det er lurt å sove nok. Noen dager orker jeg å være med på alt, andre dager må jeg hvile litt ekstra.»

Hvordan kan vi fortelle andre om epilepsi? Det er ikke alltid enkelt å forklare andre hva epilepsi er, og hvem man skal fortelle det til. Mats sier: «Noen må vite at jeg har epilepsi. Jeg har fortalt det til broren min og resten av familien, lærerne på skolen og fotballtreneren.» 
Hva kan hjelpe mot epilepsi? Her får barna en enkel

oversikt over ulike typer behandling og litt om akuttmedisin.

Hva betyr? Dette temaet gir korte forklaringer på vanskelige ord som barna kan høre når de voksne snakker sammen.

Visste du at ... inneholder fakta om epilepsi og hjernen.

EpiQuiz består av tre enkle quizer der barna får spørsmål fra e-læringsprogrammet.

For å motivere barna til å bli bedre kjent med verktøyet har vi laget et hefte med noen sitater fra EpiSnakk. Det vil i første omgang deles ut ved innleggelser på SSE, men vil gjøres tilgjengelig for flere etter hvert.

\section{Hvordan EpiSnakk kan brukes}

Barn med epilepsi som er innlagt ved SSE, har behov for tilpasset kunnskap og informasjon om sin sykdom. Det er ikke alltid opplagt hvordan det skal foregå. EpiSnakk gir enkle forklaringer som kan bidra til at barna selv forstår bedre hva epilepsi er.

$\varnothing \mathrm{kt}$ forståelse vil kunne gjøre dem tryggere, slik at de kan håndtere hverdagen sin best mulig. Når barna får $\varnothing \mathrm{kt}$ kunnskap, kan det også være lettere for dem å forklare videre til familie og venner hva epilepsi er, og hvordan de har det.

\section{$\equiv$ «Barna opplever det som positivt å kunne fortelle om sin epilepsi ved hjelp av de to gjennomgangsfigurene Mats og Maja.»}

På SSE bruker vi EpiSnakk når vi underviser i smågrupper eller har individuelle samtaler. Ved å klikke seg inn på de ulike temaene velger sykepleierne sammen med barna hva de skal snakke om.

Enkelte foreldrene har konkrete ønsker om hva barna har behov for. Vi erfarer at barna liker å være med på å velge tema og få enkle forklaringer på sykdommen sin. Noen vil gjerne vise EpiSnakk til en søster eller bror hjemme, mens andre har brukt programmet når de har snakket om epilepsi i klassen $\sin$.

Foreldre har gitt tilbakemeldinger om at barna opplever det som positivt å kunne fortelle om sin epilepsi ved hjelp av de to gjennomgangsfigurene Mats og Maja. 
Vi håper at EpiSnakk kan være et godt verktøy og gjøre det enklere for både barn, foreldre og helsepersonell å snakke om epilepsi.

Øystein Horgmo fra foto- og videotjenesten ved UiO laget illustrasjoner og animasjoner tilpasset barn. Foto fra ulike bildebaser er også brukt.

E-loeringsprogrammet ligger tilgjengelig på OUS' internettside under Spesialsykehuset for epilepsi. Der ligger også alle eloeringsprogrammene fra SSE samlet. Du finner EpiSnakk her.

\section{Referanser}

1. Lov 2. juli $1999 \mathrm{nr} .63$ om pasient- og brukerrettigheter (pasient- og brukerrettighetsloven). Tilgjengelig fra: https://lovdata.no/dokument/NL/lov/1999-07-02-63 (nedlastet 04.08.2020).

2. National Institute for Clinical Exellence. Clinical guidelines 137: The epilepsies: The diagnosis and management of epilepsies in adults and children in primary and secondary care. NICE; 2012. Tilgjengelig fra: https://www.nice.org.uk/guidance/cg137 (nedlastet 05.08.2020).

3. Pauschek J, Bernhard MB, Syrbe S, Nickel P, Neininger MP, Merkenschlager A, et al. Epilepsy in children and adolescents: disease concepts, practical knowledge, and coping. Epilepsy Behav. 2016;59:77-82.

4. Harden J, Black R, Chin RFM. Families' experiences of living with pediatric epilepsy: a qualitative systematic review. Epilepsy Behav. 2016;60:225-37.

5. Benson A, Lambert V, Gallagher P, Shahwan A, Austin JK. «I don't want them to look at me and think of my illness, I just want them to look at me and see me»: child perspectives on the challenges associated with disclosing an epilepsy diagnosis to others. Epilepsy Behav. 2015;53:83-91.

6. O'Toole S, Lambert V, Gallagher P, Shahwan A, Austin JK. «I don't like talking about it because that's not who I am»: challenges children face during epilepsy-related family communication. Chronic Illness. 2016;12(3):216-26. 
7. O'Toole S, Lambert V, Gallagher P, Shahwan A, Austin JK. Talking about epilepsy: challenges parents face when communicating with their child about epilepsy and epilepsyrelated issues. Epilepsy Behav. 2016;57:9-15.

8. Benson A, Lambert V, Gallagher P, Shahwan A, Austin JK. Parent perspectives of the challenging aspects of disclosing a child's epilepsy diagnosis to others: Why don't they tell? Chronic Illness. 2017;13(1):28-48.

9. Funderburk JA, McCormick BP, Austin JK. Does attitude toward epilepsy mediate the relationship between perceived stigma and mental health outcomes in children with epilepsy? Epilepsy Behav. 2007;11(1):71-6.

10. Kunnskapsbasert retningslinje om epilepsi. Oslo universitetssykehus; 2016. Tilgjengelig fra: https://www.epilepsibehandling.no/ (nedlastet 05.08.2020).

11. Chong L, Jamieson NJ, Gill D, Singh-Grewal D, Craig JC, Ju A, et al. Children's experiences of epilepsy: a systematic review og qualitative studies. Pediatrics. 2016;138(3):e20160658.

12. Lewis AS, Noyes J, Mackreth. Knowledge and information needs of young people with epilepsy and their parents: mixed-method systematic review. BMC Pediatrics. 2010;10:103.

13. McNelis AM, Buelow J, Myers J, Johnson EA. Concerns and needs of children with epilepsy and their parents. Clinical Nurse Specialist. 2007;21(4):195-202.

14. O'Toole S, Benson A, Lambert V, Gallagher P, Shahwan A, Austin JK. Family communication in the context of pediatric epilepsy: a systematic review. Epilepsy Behav. 2015;51:225-39.

15. Benson A, O'Toole S, Lambert V, Gallagher P, Shahwan A, Austin JK. The stigma experiences and perceptions of families living with epilepsy: implications for epilepsy-related communication within and external to the family unit. Patient Education and Counseling. 2016;99(9):1473-81. 